\title{
Urdimento
}

Revista de Estudos em Artes Cênicas

E-ISSN: 2358.6958

\section{Arte e Cidadania em Contexto Prisional}

\author{
Hugo Cruz
}

\section{Para citar este artigo:}

CRUZ, Hugo. Arte e Cidadania em Contexto Prisional.

Urdimento, Florianópolis, v. 3, n. 39, nov./dez. 2020.

DOI: http:/dx.doi.org/10.5965/14145731033920200102

Este artigo passou pelo Plagiarism Detection Software | iThenticate 


\title{
Arte e Cidadania em Contexto Prisional ${ }^{1}$
}

\author{
Hugo Cruz ${ }^{2}$
}

\begin{abstract}
Resumo
Este texto traça um breve percurso das experiências em contexto prisional desenvolvidas em Portugal nos últimos anos no contexto da ação da PELE e do seu autor. São apresentados os projetos Entrado, desenvolvido com homens no Estabelecimento Prisional do Porto e Inesquecível Emília no Estabelecimento Prisional de Santa Cruz do Bispo com a participação de mulheres no contexto de um projeto internacional. Finalmente, é abordada a experiência inserida no projeto ECOAR apoiado pelo Programa Cidadania Ativa promovido pela Fundação Calouste Gulbenkian. É discutida a relevância de uma concepção de prática artística que integre a dimensão de cidadania, nomeadamente, em contextos prisionais.
\end{abstract}

Palavras-chave: Arte. Cidadania. Prisão. Projeto.

\section{Art and Citizenship in Prison Context}

\begin{abstract}
This text traces a brief trajectory a prison theatre workshop called PELE, developed in Portugal in recent years. The projects presented are Sign in, developed with men in the Porto Prison, and Unforgettable Emilia in the Santa Cruz do Bispo Prison for women. Finally, the article discusses the ECOAR project supported by the Active Citizenship Gulbenkian Foundation. This article describes an artistic practice that integrates the dimension of citizenship in prison contexts.
\end{abstract}

Keywords: Art. Citizenship. Prison. Project.

\footnotetext{
${ }^{1}$ Este texto foi escrito originalmente para o livro Arte e Cidadania em Contexto Prisional - Percursos do Projeto ECOAR, escrito em 2017 e editado em 2018. Para esta publicação, adaptações línguisticas foram necessárias.

2 Encenador, programador cultural, diretor artístico do MEXE - Encontro Internacional de Arte e Comunidade e Mira - artes performativas. Cofundador da PELE e Nómada. Doutorando na Universidade de Porto, Portugal. Investigador do CIIE/FPCEUP e do CHAIA/UE. Consultor na Fundação Calouste Gulbenkian na Iniciativa PARTIS (Práticas Artísticas e Inclusão Social). hugoalvescruz@gmail.com
} 


\section{Arte y Ciudadanía en el Contexto Carcelario}

\section{Resumen}

Este texto traza una breve trayectoria de las experiencias en el contexto carcelario desarrolladas en Portugal en los últimos años en el contexto de la acción de PELE y su autor. Se presentan los proyectos de Registrarse, desarrollados con hombres en la Prisión de Porto y Emília Inolvidable en la Prisión de Santa Cruz do Bispo, con la participación de mujeres en el contexto de un proyecto internacional. Finalmente, se comenta la experiencia incluida en el proyecto ECOAR apoyado por el Programa de Ciudadanía Activa impulsionado por la Fundación Calouste Gulbenkian. Se discute la relevancia de una concepción de la práctica artística que integre la dimensión de ciudadanía en contextos carcelarios.

Palabras clave: Arte. Ciudadanía. Prisión. Proyecto. 
Pensar a criação artística na contemporaneidade implica pensá-la em profunda ligação com o lugar onde acontece. A relação do corpo com o lugar, que contempla o diálogo das dimensões tempo e espaço, transporta o potencial de produção de novas percepções do eu e dos outros. É clara a procura de novas formas de nos relacionarmos nos lugares que habitamos e de nos percebermos numa rede complexa mas, ainda e sempre, com base humana.

Nos cidadãos pulsa um desejo intenso de cidade, de uma outra cidade, como espaço de vivência participada e de pleno exercício de cidadania nas suas dimensões ética e estética. É neste aqui e agora, nesta procura, que se (re)inventam as práticas artísticas, numa profunda relação com o lugar onde emergem, privilegiando também os espaços não convencionais e cruzando o erudito com o tradicional. É nesta visão integrada que se cria com vontade, implícita e explícita, de transformação.

A persistente discussão entre a ideia da "arte pela arte" e da "arte com função de transformação social" perde sentido se abandonarmos um olhar que se prende nas divergências e ganharmos foco no diálogo. Mais do que perceber qual a melhor definição, o centro deve estar exatamente na tensão que se gera entre as dimensões artística e política e como estas se interpenetram de uma forma complementar. O real necessita do poético para se inspirar no sentido das mudanças e, o poético pede um real como terreno inesgotável de criação. É exatamente no espaço entre o real e o poético, o factual e o imaginado, o individual e o coletivo, que se produz o distanciamento necessário à criação de outras realidades possíveis. Esse é o espaço do estranhamento onde se podem experimentar outras formas de funcionamento do ponto de vista individual, coletivo e institucional. Poderíamos chamar a esse espaço, de forma poética Utopia, assumindo-o como algo absolutamente necessário à vida. É justamente na função simbólica da arte, que permite distinguir significado de significante, que podemos encontrar o terreno propício à mudança.

É por tudo o que se propõe nesse enquadramento, Arte e Cidadania, que traz diálogos urgentes, aparentemente inviáveis, em espaços privados de liberdade. Um olhar mais abusivo e genérico perspectiva as prisões, exclusivamente, pelas suas 
características de fecho e de periferia, como lugares de punição, onde habitam apenas as sombras de nós. É essa percepção que nos impele ao afastamento e a gerar-se a invisibilidade que se traduz, muitas vezes, numa ideia e sensação colonizadora de não-lugares. É exatamente por serem espaços periféricos, com tudo o que isso implica, que podem ser espaços com potência para a transformação, onde existe espaço concreto e subjetivo para a mobilização de outras formas de ser, estar e fazer.

A ideia dos contextos prisionais como espaços de reorganização e geradores de oportunidades, muito para além de uma visão limitada de punição, pode ser uma espécie de bolsa de respiração onde a criação artística pode atuar.

A contribuição artística só pode ser útil se for baseada num olhar mais humanizado relativamente aos cidadãos que se encontram pontualmente privados de liberdade. A partir dessa premissa, pode-se conceber que através dos processos criativos se pode gerar a oportunidade da inscrição de corpos que criam, que são vibrantes porque se expressam e que contaminam os espaços onde se relacionam, tornando-os visíveis e diversos, porque vivos.

É dentro desse espírito que evoluiu, organicamente, ao longo do tempo, e se perspectivou o trabalho desenvolvido em prisões pela PELE desde 2008. Pode-se dividir este trabalho em três fases, etapas ou degraus que tive o privilégio de ir explorando com diferentes funções e propostas.

O primeiro passo no percurso de criação em contextos prisionais, aconteceu com o projeto Entrado no Estabelecimento Prisional do Porto e que durou, simbolicamente ou não, nove meses.

Num primeiro contato com uma prisão ficam os chiches gravados pelos sentidos que se expressam na pele. As grades, os muros, o barulho das chaves, o arame farpado, o eco, os gritos, a revista, o cheiro. Com o tempo tudo isto ganha corpo, voz, cara, histórias, conflitos, tristeza, risos e uma respiração própria e secreta, diria, muito próxima do que será o essencial na vida. De uma ideia

${ }^{3}$ Reportagem sobre o projeto disponível em <https://www.youtube.com/watch?v=cAaqPbqMV20>. Acesso em: 29 set. $/ 2020$. 
romântica e ingênua, caminha-se para o confronto com homens e mulheres concretas, inundadas de resiliência e dignidade ou, por oposição, de desistência e abandono de si.

O Entrado foi também uma metáfora para essa entrada no sistema prisional, entidade subjetiva que gere cada prisão em concreto e todos os seus atores. É vivida uma sensação de estranhamento perante dinâmicas, regras e padrões idiossincráticos e que provavelmente só ganham espaço de expressão, exatamente, pela situação vivida de privação de liberdade. A sensação de que nas prisões se trocam as voltas às coisas, ou seja, que o estranhamento é provocado pelo funcionamento atípico das relações humanas, esse mesmo estranhamento que se traduz num campo arejado e fértil para a criação artística.

O Entrado mergulhou nos espaços da prisão, propondo um percurso que simbolicamente abriu os homens que the deram corpo ao desafio de se questionarem e de perguntarem ao público que os assistiu: o que é a culpa e o perdão?

Costumo dizer, e porque é verdade, que fazia teatro de uma forma antes do Entrado e passei a fazer de outra, no depois. Porque acima de tudo este foi um trabalho muito próximo da verdade, do essencial talvez, um processo e espectáculo do humano sem máscaras, mas onde apesar de tudo todos estivemos protegidos pelo teatro e pelo seu ritual.

A descoberta de que numa prisão tudo se amplia, como se ampliou o querer a um ponto surpreendente. Isso aconteceu, provavelmente, porque foi possível nos ensaios de teatro experimentar outras formas de estar, assumindo o controlo das nossas próprias vidas e, portanto, responsabilizando-nos por elas e aprendendo também, de certa forma, a cuidar delas.

Sei que podemos olhar para essas experiências como uma espécie de bolha, mas as bolhas são espaços onde nos experimentamos e normalmente nos sentimos bem, passado o medo de nos experimentarmos diferentes. As bolhas que permitem perpetuar o que está fora delas são inúteis, perdem a sua função e até o seu encanto. 
Nos dois projetos seguintes foi possível, depois dessa primeira experiência intensa, contemplar outras dimensões no trabalho realizado. No âmbito do projeto europeu PEETA (Personal Effectiveness and Employability through the Arts) ${ }^{4}$, em partilha com as experiências dos parceiros internacionais, foi desenvolvido um processo criativo que simultaneamente serviu de base a um dispositivo de certificação de competências pessoais e sociais. Como é óbvio, essa diferença colocou várias questões éticas e estéticas à equipa da PELE ${ }^{5}$, que acabou por propor adaptações ao projeto original, nomeadamente que o processo criativo e de avaliação decorressem de forma independente para não se contaminarem. Era uma oportunidade clara e única para continuar o trabalho nas prisões.

Desse projeto nasceu o espetáculo Inesquecível Emilia ${ }^{6}$ com mulheres do Estabelecimento Prisional de Santa Cruz do Bispo. Esse processo revelou outras dinâmicas, outros atores e outros espaços que determinaram os percursos construídos e nos levaram a outros lugares de nós.

Em comum, a vontade das participantes de se colocarem em jogo e a experiência do coletivo com tudo o que envolve e faz revelar. É no grupo que nos cruzamos com as nossas piores sombras, as deixamos ensombrar a luz dos outros ou, por lado, as fortalecemos ainda mais com sombrias batalhas. Mas é também no grupo, onde se constroem, como se de um laboratório se tratasse, estratégias para ultrapassar os impasses ou rever os obstáculos que impedem o desenvolvimento. Neste sentido, o processo de criação, como um ato profundamente humano, reúne uma série de ingredientes, muitas vezes em pouco e intenso tempo, que o compara à vida.

Finalmente o projeto $\mathrm{ECOAR}^{7}$, que permitiu adaptar para Portugal e para a realidade das nossas prisões, a metodologia anterior, ampliando-se o número de

4 Disponível em <https://www4.shu.ac.uk/research/cresr/ourexpertise/evaluation-personal-effectivenessand-employability-through-arts-peeta-project>. Acesso em: 29 set. 2020.

${ }^{5}$ Site do projeto disponível em <www.apele.org>. Acesso em: 29 set. 2020.

${ }^{6}$ Documentário sobre o projeto disponível em <https://www.youtube.com/watch?v=Oe7-zTOScFY>. Acesso em: 29 set. 2020.

7 Reportagem sobre o projeto, com algumas imagens, disponível em <https://www.publico.pt/2016/03/27/fotogaleria/prisao-359484>. Acesso em: 29 set. 2020. 
estabelecimentos prisionais, de participantes e de parcerias envolvidas. Esse projeto conseguiu consolidar muitas das formas de fazer experimentadas nos passos anteriores, introduziu inovações, e mais do que isso, avaliou e produziu resultados para serem analisados e servirem de base a decisões futuras. São essas informações refletidas, estruturadas, sistematizadas pelos vários atores envolvidos aos mais diversos níveis que, provavelmente, também aproximam mais este processo do que é o pleno exercício da cidadania.

Nesse último processo fica a certeza de que o tempo é realmente outro dentro de uma prisão e de que precisamos aprender a respeitar o tempo, como uma esfera necessária à respiração que acompanha as nuances do que é a mudança. O tempo foi pouco, do ponto de vista objetivo, mas foi muito subjetivamente falando, essencialmente pela surpresa com que os participantes se superaram, principalmente no momento final do processo e na apresentação pública. Esse momento de expressão pública, cheio de significados associados, da descoberta perante os outros, revela e regista o que de mais luminoso podemos ter: a possibilidade de sentir e de partilhar. Essa dimensão do sensível que torna porosa a relação que se estabelece entre o fora e o dentro de todos os que participam nestes projetos, especialmente em espaços prisionais. Esses participantes revelaram e registaram a possibilidade real dos seus poros estarem despertos ao estético, ao diferente, a mais e a melhor.

De todas essas experiências fica um respeito e profunda admiração pelos protagonistas que habitam, com diferentes papéis e intensidades, os espaçosprisão. É possível vislumbrar num cenário escuro, dominado pelo "não", depressivo e de reclusão, a vontade, a possibilidade do "sim" e da expressão, a persistência e o querer fazer diferente.

As perguntas recorrentes acerca das práticas artísticas nas prisões deixam muitas vezes no ar uma espécie de nevoeiro confusional: Para que serve a arte em contexto prisional? O que fica dessas experiências? O que muda nos reclusos?

Para essas perguntas poderiam propor-se defensivamente outras perguntas ou comparações. Ao longo deste texto, arriscaram-se algumas possibilidades de 
respostas com base nas experiências acumuladas, arrisca-se agora um final para este texto, em exercício de síntese, que se pretende em aberto e em constante construção.

Seria interessante perspectivar esses projetos como oportunidades de mudança, não só para os reclusos, mas também e necessariamente para os artistas, técnicos, direções de prisões, guardas prisionais, magistrados, universitários, políticos, para todos aqueles que, direta e indiretamente, constroem essas práticas e refletem sobre elas.

Não se pode pedir à criação artística que cumpra para além da sua função, as funções da educação, da justiça, da saúde, entre outras, assim como não se pede a essas dimensões para assumirem a construção de processos e objetos artísticos. Podemos, no entanto, tentar viver esses projetos de forma integrada e transversal, permitindo que essas funções se contaminem de forma orgânica. Para isso, é necessário que cada um saiba até onde pode ir, e como pode ir. Esse é provavelmente um desafio não só das prisões, mas do nosso país e do nosso povo. Possam as prisões, curiosamente ou não, inspirar as mudanças que todos como coletivo desejamos e ainda não sabemos operar. Possam os espaços de maior invisibilidade da nossa sociedade ser uma espécie de laboratórios de construção de cidadania impulsionadores de políticas públicas onde nos possamos rever. É aqui, em conjunto, que nos encontramos neste compromisso ético e estético de querermos mais e melhor para a existência humana.

\section{Referências}

CRUZ, Hugo; BEZELGA, Isabel; MENEZES, Isabel. Para uma tipologia da participação nas práticas artísticas comunitárias: A experiências de três grupos teatrais no Brasil e Portugal. Disponível em: <https://seer.ufrgs.br/presenca/article/view/89422> Acesso em: 29 set. 2020.

CRUZ, Hugo. Arte e Esperança. Disponível em:

$<$ https://gulbenkian.pt/publication/arte-comunidade-percursos-da-iniciativapartis/> Acesso em: 29 set. 2020. 
CRUZ, Hugo (Coord.). Arte e Comunidade. Lisboa: Fundação Calouste Gulbenkian, PELE e DGARTES, 2015.

CRUZ, Hugo (Coord.) Entrado: percursos de um projeto teatral na prisão. Santa Maria da Feira: PELE, CCTAR, Câmara Municipal de Santa Maria da Feira, 2012

MOTA, Maria (Coord.). Arte e cidadania em contexto prisional. Porto: PELE, 2018.

Recebido em: 02/10/2020

Aprovado em: 02/10/2020 